This item was submitted to Loughborough's Research Repository by the author.

Items in Figshare are protected by copyright, with all rights reserved, unless otherwise indicated.

\title{
Cumulative jeopardy when children are at risk of significant harm: A response to Bywaters
}

PLEASE CITE THE PUBLISHED VERSION

http://dx.doi.org/10.1016/j.childyouth.2015.12.021

PUBLISHER

(C) Elsevier

VERSION

AM (Accepted Manuscript)

\section{PUBLISHER STATEMENT}

This work is made available according to the conditions of the Creative Commons Attribution-NonCommercialNoDerivatives 4.0 International (CC BY-NC-ND 4.0) licence. Full details of this licence are available at: https://creativecommons.org/licenses/by-nc-nd/4.0/

\section{LICENCE}

CC BY-NC-ND 4.0

\section{REPOSITORY RECORD}

Ward, Harriet, and Rebecca Brown. 2019. "Cumulative Jeopardy When Children Are at Risk of Significant Harm: A Response to Bywaters". figshare. https://hdl.handle.net/2134/20396. 


\section{Introduction}

Our paper on 'Cumulative Jeopardy' (Brown and Ward, 2014) considered three complementary questions: how far is there a mismatch between timeframes for early childhood development and those for responses to evidence of abuse and neglect from professionals with safeguarding responsibilities in England? If a mismatch exists, why has it occurred? And how might the issues identified be addressed? We explored these questions by presenting findings from our prospective longitudinal study of infants identified as 'suffering or likely to suffer significant harm' (Ward, Brown and Westlake, 2012; Ward, Brown and Maskell-Graham, 2012). Ours is one of fifteen studies that formed a national Safeguarding Children Research Initiative (see Davies and Ward, 2012) and we were able to corroborate our data with findings from these other complementary studies (see for instance, Farmer and Lutman, 2012; Wade et al., 2011) as well as the national statistics on adoption in England (Department for Education, 2013).

Bywaters' (2015) recent response to our paper questions whether the evidence we present supports our conclusions. He argues that there are four significant reasons for doubt: methodological (our sample is unrepresentative); empirical (we present too much evidence on some risk factors and too little on others); conceptual (our analysis of professional decision-making focusses too much on decisions to separate children from birth parents) and ethical (we focus on the balance between children's rights and parents' rights, and give too little attention to the state's responsibilities towards its children).

However Bywaters uses our data selectively and misrepresents our analysis of research findings. He also questions our academic objectivity, claiming that our analysis is based on 'a presumption that decisions should be made to separate children from their birth parents' (p.70). He states that in those cases in which birth parents provided nurturing homes for infants after making significant and sustained changes to adverse lifestyles: 'it is unclear whether [we] are advocating the removal of such children ' (p.71). We have advocated no such thing. Statements such as this are a travesty both of our research findings and our interpretation of them.

We do not think we can leave Bywaters' paper unchallenged. To do so would be to negate a valuable body of evidence underpinning appropriate responses to complex 
safeguarding issues. This paper is therefore a response to Bywaters' article. It explores each of Bywaters' four reasons for doubt by drawing attention to the key findings from our study and showing how they have been misrepresented or ignored. It concludes by considering why such misunderstandings might occur.

\section{Methodological issues: is the sample too small and too unrepresentative for the findings to be worthy of report?}

The overall aim of the prospective longitudinal study on which our paper drew was to 'trace the decision-making process influencing the life pathways of a sample of very young children who were identified as being at high risk of significant harm before their first birthdays in order to improve understanding of how such decisions are reached and their consequences' (Ward, Brown and Westlake, 2012, p213). Criteria for entry to the sample were that all eligible infants had been the subject of a core assessment or a child protection enquiry under Section 47 of the Children Act 1989 before their first birthdays. Research ethics protocols also stipulated that only those babies whose parents actively indicated a willingness to participate and gave informed consent for data to be collected could be included. Fifty seven infants were recruited from 10 local authorities; 43 were followed until they were three (Ward, Brown and Westlake, 2012) and 37 until they were five (Ward, Brown and MaskellGraham, 2012); our report on the eight year follow up (36 children) will shortly be published (Brown et al, forthcoming).

Over this period, data have been collected from social work case files, annual interviews with birth parents and/or substitute carers, and single interviews with social workers, front-line and senior managers and judges. From the children's fifth birthdays, SDQ (Strength and Difficulties Questionnaire) scores have been collected and interviews held with school teachers. The Brown and Ward (2014) paper presented some of the data concerning these children and their parents at the fifth birthday follow up. The more extensive publication (Ward, Brown and Westlake, 2012) to which Bywaters also repeatedly refers, followed the children until their third birthdays and presented some additional data on the 14 children who were lost to the study between the ages of one and three, ten of them after they had been permanently placed with adoptive parents who did not wish to participate. 
Researchers currently encounter exceptional difficulties in accessing and retaining a sample such as this in the UK, an issue we have discussed elsewhere (Munro, 2008; Ward, Brown and Westlake, 2012). It is therefore unsurprising that the sample has a number of weaknesses: it is small in size, and it has suffered from attrition particularly in the first three years. Summary data concerning those children who met the eligibility criteria but whose birth parents chose not to participate also indicate that at the outset the sample was biased towards children who were identified before birth, who were placed away from home before their first birthdays and/or who received continuing support from services following a core assessment (see Ward, Brown and Westlake, 2012, pp. 220-222). We have been explicit about these weaknesses whenever we have presented findings concerning this study, including in Brown and Ward (2014) and Ward, Brown and Westlake (2012). Notwithstanding their imperfections, the data from this study are nevertheless the best available at present on the long-term experiences and outcomes for infants who have been assessed by English local authorities as suffering or likely to suffer significant harm; as far as we are aware, it is the only UK study to have followed the birth parents for such a lengthy period.

Bywaters devotes considerable attention to the weaknesses in our dataset, and takes the trouble to undertake additional analysis of some of the data we presented in the appendix to our full report (Ward, Brown and Westlake, 2012, pp. 213-222). He argues that we should 'be cautious about drawing conclusions from such a small and unrepresentative sample' but suggests that, in Brown and Ward (2014), we have thrown such caution to the winds, making exaggerated statements about the timeliness of decision-making and its consequences for children without clarifying that these conclusions are drawn from an inadequate database.

In response we would argue that although we acknowledge the weaknesses in the dataset, they are not as great as Bywaters would have us believe, for three reasons. Firstly, his additional analysis of our data is inaccurate. Anonymous data on all children who were eligible for recruitment to the sample were provided by four local authorities: of the 639 children whom they identified as eligible, 29 (4.54\%) were recruited. There were wide differences in the numbers of eligible children in these authorities, which included two of the largest in the study. Extrapolating these data to the sample as a whole, we concluded that the 57 children in the full sample 
represented about $4 \%$ of those who were eligible (see Ward, Brown and Westlake, 2012, p.34; p.219), However Bywaters takes a misleading sentence from our Appendix (p. 215) which suggests that the 4\% relates to the number of parents who expressed an interest in their child being included rather than the number who eventually did take part, and concludes that the initial sample represented only $2.7 \%$ of eligible children. We are grateful to Bywaters for highlighting this issue which will be clarified in subsequent editions of the book.

Bywaters' additional analysis of the rate of attrition is also erroneous, for his calculations do not include those children who we continued to track through case file information, court papers, assessments and other sources when parents or early carers were no longer available for interview, and this leads him to exaggerate its extent. Although we were only able to retain contact with 33 birth parents and temporary carers, we were able to follow 43 children, together with birth parents and/or long-term substitute carers, for three years, representing about 3\%.of those children who were eligible for selection (not 1.67\% as Bywaters claims). He also asks whether any local authorities dropped out of the study: none did.

Secondly, as we made clear in Ward, Brown and Westlake (2012), the sample is biased, but it is biased towards those infants who were at greatest risk of significant harm, and so professional decision-making in these cases had particularly farreaching consequences.

Thirdly, while we agree with Bywaters that our numbers are too small to provide more than indicative data, the findings presented in Brown and Ward (2014) are not left to stand alone, but are set alongside data from other complementary studies from the same research initiative together with the national statistics on adoption, which corroborate them (see Brown and Ward 2014, Section 7: Corroborative evidence). For instance, data from the national statistics on adoption confirm our evidence of children experiencing the double jeopardy of lengthy exposure to abuse and neglect followed by disrupted attachments to temporary carers with whom they stayed for several months before being placed in an adoptive home. That is why we were able to come to more robust conclusions in this paper than in other publications. 


\section{What are the key findings and their implications?}

In our view, the following findings are most significant in responding to the questions explored in Brown and Ward, 2014.

At around the time of their births, and again at ages three, five and eight, we classified the children in the sample into groups according to the presence of risk and protective factors that have been shown to be associated with a greater or lesser likelihood of recurrent abuse (see Hindley, Ramchandani and Jones, 2006). By the time they were three, nearly three quarters (31/43: $72 \%$ ) of the sample were thought to be adequately safeguarded in that they were either living with parents who had succeeded in overcoming complex combinations of risk factors and were now able to provide nurturing homes (16/43: $\left.37 \%{ }^{1}\right)$; had been permanently separated from abusive or neglectful birth parents who had shown little or no capacity to change (13/43: $31 \%)$; or were placed with supportive relatives under shared care arrangements (2/43: 5\%). However over one in four of the children (12/43: 28\%) were living with birth parents who showed little capacity to change and who continued to place them at risk of significant harm. By the time they were five the picture was less positive in that a number of the parents who had made substantial changes for the first three years of their children's lives were no longer able to safeguard them adequately, and three of the six permanent placements with relatives were becoming unstable.

This was a high risk sample, many of whom had been identified before they were born as likely to suffer significant harm. Although professionals made extensive efforts to support parents and ensure that these infants were adequately safeguarded, 24 (56\%) of the 43 children in the follow-up sample had experienced abuse or neglect by the time they were three. The consequences of maltreatment were by now apparent and by their third birthdays over half (16/28: 57\%) of the 28 children for whom sufficient data were available, and who did not have special health care needs, were displaying behaviours that were of concern to their carers. By the time they were five, the incidence of children with SDQ scores in the abnormal range was three times that found in a normative population. Poor speech and language development compounded their difficulties, and further reduced their chances of

\footnotetext{
${ }^{1}$ This is the correct percentage - it is reported incorrectly in Brown and Ward, 2014, Table 1.
} 
thriving at school. The qualitative data from this study reveal children who were so aggressive that they could not safely be left alone with younger children or family pets; children who routinely trashed their bedrooms or their classrooms; children who self-harmed at the age of three; and children who at five years old were not yet toilet trained and whose speech lagged far behind that of their peers (see Brown and Ward, 2014; Ward, Brown and Westlake, 2012; Ward, Brown and Maskell-Graham, 2012; Brown et al., forthcoming).

The data also indicate that emotional and behavioural difficulties were likely to be related to the duration and extent of exposure to maltreatment: such difficulties were more evident amongst those children who had been late separated from (5/8: 63\%), or remained with (7/9: 78\%), birth parents who had been unable to overcome those factors that placed them at risk of significant harm than amongst those children living with parents who had succeeded in making substantial changes to adverse lifestyles and relationships (4/11: 36\%) (see Ward, Brown and Westlake, 2012, pp141-142). Although these subsets are too small for the data to be more than indicative, they corroborate findings from other studies which show that delaying the decision to separate abused and neglected children from birth parents in the expectation that their circumstances will change can jeopardise their chances of achieving stable placements in foster care or adoption as well as their long-term wellbeing (see Selwyn et al., 2006; Ward, Holmes and Soper, 2008; Wade et al., 2011). A longitudinal study of outcomes for abused and neglected infants placed in care in France has also recently produced very similar findings to those reported here, but with a larger sample of 134 children (see Rousseau et al., 2015).

Data reported in Brown and Ward (2014) and more extensively in Ward, Brown and Westlake (2012) also show that delays in the adoption process further compromised the children's wellbeing: $60 \%$ of those children who were eventually separated from birth parents experienced the double jeopardy of lengthy exposure to abuse and neglect followed by the disruption of a secure attachment to a temporary foster carer with whom they remained for months (and sometimes years) before reaching an adoptive placement. Again these findings are no more than indicative, but they are corroborated by data from other studies (see Selwyn et al., 2015), by the national statistics, and by recent studies in France (Rousseau et al., 2015) and Canada (Gauthier et al., 2004). The national statistics referred to in Brown and Ward (2014) 
showed that children who were eventually placed for adoption in England and Wales in 2013 spent an average of 14 months living with their birth families and then a further 22 months in the limbo of temporary care before being placed with an adoptive family at about three years old (Department for Education, 2013). Van den Dries and colleagues' (2009) meta-analysis of findings from 50 studies showed that infants are significantly more likely to develop a secure attachment to adoptive carers if they are placed with them before their first birthdays.

In our view the findings reported in Brown and Ward (2014) indicate that a high proportion of this sample of children was not adequately safeguarded from harm. The data do not necessarily indicate that more children should be separated from birth families. Contrary to Bywaters' assertions, this is not our interpretation. In the wider study, to which Bywaters also refers, we present data concerning the limited availability of social work and other professional support to birth parents, and argue that had these been provided for longer, and withdrawn less abruptly, the children might have been better safeguarded at home (see Ward, Brown and Westlake, 2012, p.165-168). The findings do, however, indicate that the longer children are exposed to extensive abuse or neglect, the greater the risk to their long-term development; that where parents show little capacity to change, and children can only be safeguarded through separation, lengthy delays in reaching that conclusion further compromise their wellbeing; and that delays in the adoption process jeopardise children's chances of becoming securely attached to adoptive parents.

These are troubling findings. Bywaters makes no mention of them. However they are corroborated by numerous other studies as well as by national statistics, and should not be discounted because the sample is small and biased towards children at greatest risk of significant harm.

\section{Empirical issues: would the findings have been different if we had included data on poverty?}

Bywaters argues that we should have collected systematic data concerning parents' material circumstances, including their finances, the neighbourhood in which they lived, the 'availability of local services and facilities, transport systems, parks and 
green spaces'. In his view this omission reflects 'a wider failure of child welfare professionals to take sufficiently seriously the impact of what, in studies of health inequity are called 'social determinants' on mothers' and fathers' capacity to parent effectively (p.70).

Although material deprivation formed the background to almost all the children's lives, these issues did not feature largely in parents' responses to interview questions in the first years of the study, when their predominant concerns were focussed on their fears that their children might be removed. Data from interviews with parents and primary carers held in later years, when separation was no longer such a critical issue, show that impoverished material circumstances and inadequate incomes have posed an increasing challenge as the children have grown older, family sizes have increased and austerity measures introduced to reduce welfare dependency have been implemented nationally; as a result they feature more strongly in the later reports (see Ward, Brown and Maskell-Graham, 2012; Brown et al., forthcoming). We accept that more extensive and systematic data on social determinants would have been valuable, although the considerable practical difficulties of collecting such data in a study with a limited budget and a strict timescale might well have proved insurmountable.

However Bywaters' argument, that deprivation factors should have been included in our framework for classifying children according to the likelihood of significant harm, is unconvincing. This classification was based on Hindley, Ramchandani and Jones' (2006) rigorous systematic review of studies of outcome following identification of child abuse and neglect, which identified factors such as parental substance misuse, paranoid psychosis or personality disorder, inter-parental conflict and violence and childhood experiences of maltreatment as associated with an increased risk of recurrent abuse. Bywaters argues that the Hindley study is unusual in that it did not identify relative poverty as a risk factor, implying that this is a flaw, but the studies that he references as alternatives focus on the relationship between material disadvantage and involvement with children's services, not the relationship between material disadvantage and recurrent maltreatment or significant harm, and none are systematic reviews or meta-analyses. 
Bywaters has published extensively on inequalities in welfare $(2013,2014)$. In his view 'parental mental ill health, substance abuse, domestic violence and a childhood history of involvement with children's services - should be viewed as proximal factors, in health terms similar to smoking, diet and exercise, factors which reflect underlying social determinants rather than being primary causes of family troubles' (Bywaters, 2013, p.19). However the undoubted importance of poverty and poor material circumstances is not a reason for assuming that these were the primary causes of these children's experiences of abuse and neglect. Our study included infants who witnessed and were sometimes caught up in inter-parental violence; who were subject to repeated and sometimes life-threatening physical abuse; who were thought to be being groomed by paedophiles; whose parents locked them alone in the house overnight; who had been allowed to play with a methadone bottle or been given illicit drugs to taste on a spoon. These experiences were directly related to complex combinations of those factors included in our risk analysis framework: for instance parents who physically abused their infants had been abused themselves as children and/or had severe mental health problems and/or were drunk or under the influence of drugs at the time. Deprivation was part of the context within which much abuse occurred, and no doubt exacerbated parental problems, but it was not the primary causal factor.

This is not to downplay the significant impact of material deprivation in the lives of the families we studied. Bringing up a child on an inadequate income and in an impoverished and sometimes dangerous environment is extremely stressful and thereby increases the likelihood of domestic abuse or parents' mental ill-health that are directly associated with child maltreatment. However the vast majority of poor families do not abuse or neglect their children; for example, Naughton and colleagues' (2013) systematic review of the consequences of neglect identified 23 case control studies in which the comparison population of children who were not neglected were experiencing the same levels of poverty and material deprivation as those who were.

The underlying question is whether adding indicators of deprivation to our framework would have altered our primary findings. Using the factors identified by Hindley, we were able to classify the children into groups which were at greater or lesser risk of significant harm. The framework was successful in enabling us to identify at an early 
age those children whom professionals later decided could not safely remain at home; it also enabled us to identify early those children whose parents made significant and sustained changes and were able to safeguard them effectively. Professional decisions for children in both our severe and our low risk categories were broadly in line with the empirical research evidence used to construct the framework, indicating that although decisions to place children apart from birth families may be subject to lengthy delays, they are not made arbitrarily - one of the issues we had been asked to explore.

The framework was not so successful in identifying children for whom the risk of significant harm was to fluctuate or increase during the course of the study. Including deprivation factors might have improved the identification of these parents and analysis of such factors could have indicated areas where parents might have been better supported. However, improved material circumstances did not necessarily resolve parents' problems. For instance some parents who moved out of overcrowded housing or dangerous neighbourhoods also moved away from support networks. Loneliness and isolation made them vulnerable to alcohol abuse, or to reestablishing a relationship with a violent partner. The re-emergence of factors such as these was directly associated with continuing abuse and neglect, an unlooked for consequence of their change of circumstances (see Ward, Brown and Maskell Graham, 2012; Brown and Ward, 2014).

Moreover, even if the inclusion of deprivation factors in our framework had improved our classification, this would not have altered our key findings. To reiterate, those reported in Brown and Ward (2014) indicate that a high proportion of children in the study were not adequately safeguarded from harm; that delays in reaching the conclusion that some parents would be unable to make the changes that would protect their children from abuse and neglect within an appropriate timeframe further compromised the wellbeing of those who could not be safely looked after at home, and that delays in the adoption process made it less likely that those who were permanently separated would become securely attached to adoptive parents. However, these are findings that Bywaters chooses to ignore. 


\section{Conceptual issues: do we confuse the issue of effective decision-making with a presumption that decisions should be made to separate children from their birth families?}

Bywaters acknowledges that some children require protection through separation. However he claims that we regard only those decisions that result in separations as effective judgements and insinuates that our analysis of our findings is biased by an ideological presumption in favour of separation. We do not accept this argument which, once again, is based on a failure to engage with key data items, extremely selective presentation of others and a misrepresentation of our analysis.

Firstly, the children in the study were all very young and, as we have seen, the sample was skewed towards those who were at greatest risk of significant harm. These are the children for whom the fundamental decision is whether or not they can safely remain at home, particularly in the early years when they are most vulnerable to compromised development, injury and death as a result of maltreatment. The study was funded as part of a research initiative set up in response to one high profile death (Laming, 2003), and extended following another (Haringey, 2010). One of our specified aims was to 'explore how, and at what point, the decision between providing family support services or placements is made' (Ward, Brown and Westlake, 2012, p.213) and another was to 'add to the evidence base upon which professionals can draw in deciding which children require permanent out-of-home placement and which can safely remain with their birth parents' (p.31). It is therefore unsurprising that the decisions upon which much (though by no means all) of the study focuses are those concerning separation and placement away from home.

Brown and Ward (2014) focuses on one specific issue - how lengthy timeframes for deciding to look for and then finding permanent placements for children whose parents appear unable to ensure their safety at home are out of kilter with timeframes for early childhood development. The paper presents findings from a wide range of studies concerning the impact of abuse and neglect on children's development in the early years, and shows how delayed professional decisions when parents do not show sufficient capacity to change harmful behavioural patterns further compromise their life chances. We acknowledge that in this paper we focus on decisions that result in separations, but in our view the data that we present 
supports Bywater's own view that 'some children will require protection by separation from their birth parents and placement in an alternative family. When this is known to be necessary, the least delay possible is almost always advantageous' (p.72). Bywaters offers no evidence to support his claim that 'the case being advanced goes well beyond that proposition' (p.72), and it is only by ignoring the data that we present on the children's experiences and their impact that he can claim that this paper shows a presumption towards separation.

Turning to the reports on the full study, Bywaters criticises us for focussing too little on the small group of children whose parents successfully overcame significant difficulties to provide them with nurturing homes. He measures our interest by the number of pages we devote to this group in our full report (and undercounts by at least 50\%). His point appears to be that our supposed ideological bias towards separation leads us to pay too little attention to the important lessons to be learnt from the parents of these children and the services that helped them to overcome their difficulties.

Fourteen parents (or sets of parents) succeeded in making and sustaining significant changes to lifestyles and relationships and were able to safeguard their children adequately at least until they were three (discrepancies in numbers noted by Bywaters are accounted for by the presence of sibling groups and by differences in the composition of this floating sample at specific time points: a slightly different population of parents could be accessed at the children's fifth birthdays than when they were three). The parents who were able to safeguard their children form a diverse group, including those who made radical changes to their own lifestyles and relationships as well as those whose own behaviour patterns had never posed a risk to their children, but who succeeded in protecting them from partners who abused them. Many of these parents' stories are inspiring, but we have been careful not to give too much weight to individual experiences, not, as Bywaters implies, because we have an inherently negative focus, but because we have concerns that too much credence will be given to findings that may not prove to be generalisable. We have, however, presented data on those factors that appear to be common to this diverse group of parents and that distinguish them from the significantly larger group who were unable to make sufficient changes to safeguard their children. The key factors that appeared most to influence these different trajectories at the children's third 
birthdays include the prevalence of internal and external risk factors, the availability of protective factors including informal support networks, the development of insight, and the timing of parental change (see Ward, Brown and Westlake, 2012, pp 124138).

Bywaters ignores these data. Instead, our supposed bias towards separation leads him to criticise us for saying 'little or nothing about the nature and content of packages of support provided as an alternative to care, their adequacy for meeting the needs of children and parents, whether some kinds of supportive interventions were more effective than others, whether the support packages and specialist services agreed in case conferences were carried out and adequately resourced or how they affected parents and children' (p.70). It would have been useful to present this information. However anyone who has undertaken empirical research of this nature in English local authorities will be aware that these data are not routinely or adequately recorded on case files or collated centrally; practitioners rarely use formal measures of effectiveness - barely at all in this study - and that social workers change so frequently that they do not have personal knowledge of what has been offered or accessed by specific families over a lengthy time span. The only possible sources of these data were the parents, who were unable to provide precise information that could be quantified. We have reported the information they gave us.

Our full report includes a detailed discussion of why some parents found some services helpful and some did not (see Ward, Brown and Westlake, 2012, pp. 178201). Bywaters ignores this discussion. He also neglects to mention that we collected robust quantitative data on child protection plans, the length of social work involvement, and the frequency with which social work case files were opened and closed. Fifty per cent of the child protection plans where children in our sample remained with birth parents were for 32 weeks or less, and all but three for less than a year; $70 \%$ of social work case files were closed by the time the children were three, and almost half of those that were still open by then had been re-opened following closure and a subsequent referral (Ward, Brown and Westlake, 2012, p. 96, pp.1658). These data indicate that professional support was often too sporadic and too short term to provide sufficient help for parents who were going through complex change processes. In the words of one social worker: 'we don't prevent, we do blitzkrieg intervention, and we don't always have the necessary time to follow up and 
they relapse' (idem, p.166). The data indicate that such parents require more intensive, focussed support if they are to overcome the entrenched and complex difficulties that beset them, and make and sustain the changes necessary to provide a nurturing home within a child's timeframe. They do not indicate that more children should come into care, but that more needs to be done to protect them from harm.

We also present data indicating that neither birth parents, nor foster carers, nor teachers receive adequate expert support to enable them to help children overcome emotional and behavioural difficulties related to previous experiences of maltreatment and that jeopardise their wellbeing whether they are at home, in foster care or at school (see Ward, Brown and Westlake, 2012; Ward, Brown and MaskellGraham, 2012; Brown and Ward, 2014). A key message from our study is that more support needs to be provided to safeguard children who have experienced significant adversity whether they are living with birth parents or placed permanently away from home.

However Bywaters ignores these messages. Instead, his contention that we have a bias towards separation leads him to state that:

'it is unclear whether the authors are advocating that these children [living at home and considered safeguarded by parents in the low risk group] should also have had early decisions for permanent alternative placements and whether they are able to determine in advance which children will be safeguarded if they remain at home and with what packages of support. If they cannot, it is unclear whether they are advocating the removal of such children as 'collateral damage', a necessary consequence of an approach which highlights risk and advocates removal' (p.71).

There is nothing in our data or our interpretation of it that supports this statement, and we are at a loss to understand how Bywaters might have reached such an extraordinary conclusion. It is clear from our data that these children were safeguarded by parents who made substantial changes within an appropriate timeframe and who were able to provide nurturing homes for the first three years of our lives. Neither we nor anyone else has argued that they should have been removed. 
Perhaps Bywaters is suggesting that speedier decision-making may result in some children being unnecessarily removed from birth families who would have been able to provide nurturing homes within an appropriate timeframe. If that is the case - and his argument is unclear - then this is a valid point. However, as we have pointed out, our purpose is not to advocate removal but to argue that better use of research evidence concerning the likelihood of abuse and neglect and its consequences might improve decision-making. Making premature decisions to separate children from birth parents, based on limited understanding of the factors indicative of parental capacity to change, can be as detrimental as delaying decisions because robust evidence concerning the likelihood of significant harm has not been understood.

\section{Ethical issues: has the balance between parents' rights and children's rights shifted so that our findings are no longer relevant?}

British child welfare legislation reflects the principle embodied in the UN Convention on the Rights of the Child that children are best looked after within the family. In Ward, Brown and Westlake (2012) we presented interview data that indicate that the focus on family preservation made it particularly difficult for professionals to identify those few children whose needs could not be met within the birth family and who could only be adequately safeguarded through placement away from home.

Confusion as to whether the practitioners' role was to safeguard the birth family or the individual children within it was a major cause of delayed decisions to protect children from harm through separation. Seen from the perspective of the Human Rights Act 1998, in our view there was an imbalance between the weight given to the parent's right to respect for private and family life (Article 8) and the child's rights to be protected from inhuman and degrading treatment (Article 3), and to a family life, if necessary in a permanent out of home placement. For instance, scrutiny of files and court documents found 35 specialist assessments of parenting capacity and no paediatric assessments of the impact of parental problems on the child. Repeated assessments of parenting capacity in families where children were at severe risk of harm and there had been little evidence of change were also a major cause of delayed decisions to safeguard children through separation (Ward, Brown and 
Westlake, 2012, pp150-160), a finding corroborated by Masson and colleagues (2008).

Our sample was recruited in 2007-8, before the global financial crisis and the death of Peter Connelly, a baby who died following months of physical abuse and neglect from his birth mother and her partner. Following the resulting media frenzy, there have been large increases in the number of Section 47 child protection enquiries, initial child protection conferences and child protection plans. Large increases in the numbers of children in care and placed for adoption may also have been fuelled by austerity measures which have seen the retrenchment of family support services and by the introduction of numerous policy initiatives designed to support adoption. Bywaters presents the national data on these issues and suggests that our ethical framework is both outdated because the tendency to favour birth parents that we identified no longer persists and flawed because our argument that children have a right to an alternative family where necessary fails to take into account the state's responsibility to meet other human rights, including the provision of social services.

We agree with Bywaters that the statistical information he presents could indicate that professionals may no longer favour birth parents to the extent that we identified. However, in our view that is not the fundamental issue. The key question for those whose primary concern is the welfare of children is whether the additional and more intrusive interventions reflected in the statistics indicate that fewer children are now suffering or likely to suffer significant harm. We think that this is unlikely. As Bywaters himself argues, the large increase in the number of child protection investigations that do not result in a child protection plan indicates that resources that might have been used to provide more extensive family support are being diverted into unnecessary and alienating investigations. Moreover, while there are significantly more children who are now the subjects of child protection plans, the percentage of children whose plans have lasted for three months or less has risen from $14.8 \%$ in 2010 to $20.3 \%$ in 2014 (see DFE, 2010, 2014), indicating that the tendency to close cases prematurely that we noted may well have increased as pressures on services have grown.

There are similar issues with the interpretation of statistics on entry to care. Ours was one of three empirical studies in the Safeguarding Children Research Initiative 
that focussed on social work interventions when children were at risk of significant harm (Farmer and Lutman, 2012; Wade et al., 2011; Ward, Brown and Westlake, 2012). All of them found extensive evidence of professionals providing intensive, though often sporadic, support and giving parents repeated opportunities to demonstrate that they could safely look after a child, frequently in the face of substantial evidence to the contrary and regardless of the impact of long-term exposure to abuse and neglect on their children's wellbeing. Farmer and Lutman (2012) estimated that this had happened in nearly two fifths (38\%) of cases (pp.7879). The increased numbers of children coming into care since the data from these studies were collected could indicate that more children whose parents are unable to protect them from harm are now better safeguarded. However the average duration of a care episode has dropped by 2.5 months since 2010. Although this would be beneficial if children were returning to families who were now better able to safeguard them, there is increasing evidence that services such as mental health provision, that might have supported parents throughout reunification, are being cut back, and little evidence that reunification has improved since Wade and colleagues (2011) found that the majority of abused and neglected children who remain in care do better in terms of stability and welfare outcomes than those who return home.

Finally it is possible that more children are better safeguarded because there has been an increase in the numbers placed for adoption. The national statistics show that a higher proportion of children who are placed for adoption now come into care before their first birthdays, indicating that fewer may be subject to lengthy exposure to abuse and neglect before separation. However infants are still subject to lengthy delays between entry to care and permanent placement, risking the double jeopardy of maltreatment followed by sequential attachment disruptions. Moreover there are concerns that the current policy focus on adoption pays insufficient regard to the other elements in the system of child protection (Ward, 2014). The rate of adoption disruptions is currently very low (3.2\%) (Selwyn et al, 2015). However adoption is only suitable for a small proportion of looked after children and pressures to increase their numbers could result in an unanticipated increase in disruptions, particularly if adoption support services are not commensurate with need. Moreover, pressures on local authorities to place increasing numbers of children for adoption may result in abuses of human rights and litigation from those parents who would have been able 
to make the changes necessary to meet their needs with the support of professionals (see Ward, 2014). The Supreme Court has already criticised policies intended to reduce financial support to families as in breach of the UNCRC, as they deprive some children of provision for their basic needs (R (SG and others) v SSWP, 2015). If children are placed for adoption because family support services have been cut and financial support reduced, the state may be in breach of its responsibilities under human rights legislation, as Bywaters suggests.

Nevertheless, the drive to increase the numbers of children placed for adoption does not necessarily indicate, as Bywaters also argues, that there has been a major shift away from the weight given to parents' rights since our study began. Although he is correct in stating that the percentage of children adopted increased by $56 \%$ between $2007 / 8$ and 2013/14, Bywaters' use of statistics masks the very low numbers involved (a peak of about 5,000 from a care population of 69,000 in 2014) (Department for Education, 2014). There is also more recent evidence showing that new placement (for adoption) orders have been falling: from 1550 in the three months preceding $30^{\text {th }}$ September 2013 to 850 in the three months preceding $31^{\text {st }}$ March 2015, a decrease of 45\% (Adoption Leadership Board, 2015). These changes reflect ongoing debates in the courts concerning the appropriate balance between the rights of parents and children and the responsibilities of the state (see Adoption Leadership Board 2014).

So although Bywaters may be correct in arguing that shifts in the balance of rights and major societal changes provide a different context today from that in which the children in our sample were recruited eight years ago, the changes may not be as great as he surmises. Moreover we do not accept, as he implies, that such changes mean that our study is now so out of date as to have little relevance today. He states that 'it is not clear what conclusions can be drawn in 2014 from the small and unrepresentative sample of cases that the authors recruited in 2006-7' (Bywaters, 2015, p.72). But he forgets that ours is a prospective longitudinal study, tracing how decisions made in the early years have continued to influence the children's trajectories as they grow older. The children in the sample are now eight years old and we are continuing to follow them. Our current report provides new evidence of how professionals and parents are still trying to safeguard them from future harm as 
well as to help them overcome the consequences of past maltreatment (see Brown et al., forthcoming).

\section{Conclusion}

We do not therefore accept the criticisms that Bywaters' makes of our study on methodological, empirical, conceptual or ethical grounds. His paper has many inaccuracies and misrepresentations, as well as misperceptions of the limitations of empirical research in English children's services. For instance, his calculations of the relative size and attrition rates of our sample are incorrect, and he misrepresents our analysis of the data on parents who were able to overcome complex problems and provide nurturing homes for their children. He ignores much of the data that we present in Brown and Ward (2014) and he engages only minimally - and extremely selectively - with that which we present in Ward, Brown and Westlake (2012). He produces no alternative interpretations of our findings on, for instance, the prevalence of significant emotional and behavioural problems in our sample, and no additional data that might challenge the research evidence which we present. His fundamental criticism appears to be that we did not undertake the study that he would like to have seen - on 'how to maximise children's wellbeing, individually and at the population level' (Bywaters, 2015, p.72) - but instead that we undertook the study we were contracted to do - an analysis of professional decision-making and its consequences when children are at risk of significant harm.

However to refute Bywaters' paper on purely academic criteria is to miss the crucial point that debates about policy in this domain have an unavoidable political dimension. We can see the effect of this in Bywaters' description of our analyses of research findings as 'serious charges' and 'allegations' (p.68) and his presentation of the largely positive findings from Forrester and colleagues' (2009) meticulous review of the British research evidence on the outcomes of care as a 'claim' used to support a political 'prescription - more children to be separated from birth parents, removed earlier and more speedily'. Perhaps it is a political stance which leads Bywaters to conflate contested adoptions in the UK, where the courts can only make placement orders against the wishes of parents if there is evidence that the child is 'suffering or likely to suffer significant harm' with the discredited practices in Australia in the 
1960s and 1970s, in which new born babies were systematically removed from young unmarried women by means of threats, coercion and deception (see Kenny et al, 2012), referring to them both as 'forced' adoptions (p.72).

Once positions are polarised it becomes more difficult to appraise research evidence. Because our findings indicate that some children were not safe while remaining with their birth parents - and in our view at least three of our sample might well have died had they not been separated - we are forced into a position in which we can be accused of being advocates of policies designed to separate children from birth parents, regardless of 'collateral damage'. Our findings do not support that position and nor do we.

The irony of Bywaters' attack is that, on the basis of our research findings, we too have challenged government policies that increase the stressors on vulnerable families and make abuse and neglect more likely (Ward, 2012a, 2015). We have also argued that placing maltreated children in care or in adoptive families can only be a reactive solution to societal problems that include high levels of both absolute and relative poverty, inadequate and overcrowded housing, and fractured communities as well as the parental problems that have been so frequently identified (see Ward, 2012a; 2012b, Brown et al., forthcoming). We agree with Bywaters that these issues urgently need to be addressed. We should be fighting together to improve policies to support vulnerable children and their families, not fighting one another.

\section{Acknowledgement}

The study was funded by the Department for Education, England

\section{References}

Adoption Leadership Board (2014) Impact of Court Judgments on Adoption, London: Department for Education 
Adoption Leadership Board ( 2015) Adoption Leadership Board headline Measures and Business Intelligence Quarter Four 2014-2015. Accessed on 15/12/2015 at https://www.gov.uk/government/uploads/system/uploads/attachment_data/file/45619 3/ALB_Business_Intelligence_Quarter_4_2014_to_2015.pdf

Brown, R. and Ward, H. (2014) 'Cumulative jeopardy: How professional responses to evidence of abuse and neglect further jeopardise children's life chances by being out of kilter with timeframes for early childhood development.' Children and Youth Services Review Volume 47, 3, 260-267.

Brown, R., Ward, H., Blackmore, J., Thomas, C. and Hyde-Dryden, G. (forthcoming) Infants suffering, or likely to suffer, significant harm: A prospective longitudinal study: age eight follow-up. London: Department for Education.

Bywaters, P. (2015) 'Cumulative jeopardy? A response to Brown and Ward.' Children and Youth Services Review 52, 68-73.

Bywaters, P. (2013) 'Inequalities in child welfare: Towards a new policy, research and action agenda.' British Journal of Social Work, 1-18.

Bywaters, P., Brady, G., Sparks, T. and Bos, E. (2014) 'Child welfare inequalities: New evidence, further questions.' Child and Family Social Work Accessed on 15/12/15 at http://onlinelibrary.wiley.com/doi/10.1111/cfs.12154/epdf.

Davies, C. and Ward, H. (2012) Safeguarding Children across Services: Messages from Research. London: Jessica Kingsley Publishers.

Department for Education (2010) Children in need in England, including their characteristics and further information on children who were the subject of a child protection plan (2009-10 Children in Need census - Final). Accessed on 15/12/2015 at https://www.gov.uk/government/statistics/children-in-need-in-england-includingtheir-characteristics-and-further-information-on-children-who-were-the-subject-of-achild-protection-plan-2009.

Department for Education (2014) Characteristics of Children in Need 2013-2014 https://www.gov.uk/government/statistics/characteristics-of-children-in-need-2013-to$\underline{2014}$ 
Department for Education (2013) Children Looked After in England (including adoption and care leavers) - year ending 31 March 2013.SFR 36/2013. Accessed on $13 / 08 / 15$ at

https://www.gov.uk/government/uploads/system/uploads/attachment data/file/21921 0/sfr20-2012v2.pdf.

Farmer, E. and Lutman, E. (2012) Effective Working with Neglected Children and their Families: Linking Interventions with Long-term Outcomes. London: Jessica Kingsley Publishers.

Forrester, D., Goodman, K., Cocker, C., Binnie, C. and Jensch, G. (2009). What is the Impact of Public Care on Children's Welfare ? A Review of Research Findings from England and Wales and their Policy Implications. Journal of Social Policy, 38, 3, 439-456.

Gauthier, Y., Fortin, G. and Jéliu, G. (2004) 'Clinical application of attachment theory in permanency planning for children in foster care: The importance of continuity of care.' Infant Mental Health Journal, 25, 4, 379-396.

Haringey Local Safeguarding Children Board (2010) Serious Case Review: Child A March 2009. London: Department for Education.

Hindley, N., Ramchandani, P.G. and Jones, D.P.H. (2006) 'Risk factors for recurrence of maltreatment: A systematic review.' Arch Dis Child, 91, 9, 744-752.

Kenny, P., Higgins, D., Soloff, C., and Sweid, R. (2012). Past Adoption Experiences: National Research Study on the Service Response to Past Adoption Practices (Research Report No. 21). Melbourne: Australian Institute of Family Studies.

Laming, H. (2003) (Cm 5730) The Victoria Climbie Inquiry: Report of an Inquiry by Lord Laming. London: The Stationery Office.

Masson, J., Pearce, J., Bader, K., Joyner, O., Marsden, J. and Westlake, D. (2008) Care Profiling Study: Research Series 4/08. London: Ministry of Justice.

Munro, E.R. (2008) 'Research governance, ethics and access: A case study illustrating the new challenges facing social researchers.' International Journal of Social Research Methodology, 11, 5 429-439. 
Naughton, A., Maguire, S., Mann, M., Lumn, C., Tempest, V., Gracias, S. and Kemp, A. (2013) 'Emotional, behavioural and developmental features indicative of neglect or emotional abuse in pre-school children: A systematic review.' JAMA Pediatrics, $167,8,769-775$.

Rousseau, D., Roze, M., Duverger, P., Fanello, S. and Tanguy, M. (2015) Etude sur le Devenir à Long Termes des Jeunes Enfants Placés à la Pouponnière Sociale Saint Exupéry Entre 1994 et 2001. Rapport Recherche St-Ex 2013-2014. Angers: Unite de Psychologie de l'Enfant et de l'Adolescent.

Selwyn, J.T., Sturgess, W., Quinton, D.L. and Baxter, C. (2006) Costs and Outcomes of Non-Infant Adoptions. London: British Association for Adoption and Fostering (BAAF).

Selwyn J. Meakings S. and Wijedasa D (2015) Beyond the Adoption Order: challenges interventions and adoption disruption. London : British Association for Adoption and Fostering (BAAF).

Van den Dries, L., Juffer, F., Van IJzendoorn, M.H. and Bakermans-Kranenburg, M.J. (2009) 'Fostering security? A meta-analysis of attachment in adopted children.' Children and Youth Services Review 31, 410-421.

Wade, J., Biehal, N., Farrelly, N. and Sinclair, I. (2011) Caring for Abused and Neglected Children: Making the Right Decisions for Re-unification or Long-term Care. London: Jessica Kingsley Publishers.

Ward, H., Holmes, L. and Soper, J. (2008) Costs and Consequences of Placing Children in Care. London: Jessica Kingsley Publishers.

Ward, H., Brown, R.C. and Maskell-Graham, D. (2012) Young Children Suffering, or Likely to Suffer Significant Harm: Experiences on Entering Education. London: Department for Education.

Ward, H., Brown, R. and Westlake, D. (2012) Safeguarding Babies and Very Young Children from Abuse and Neglect. London: Jessica Kingsley Publishers. 
Ward, H. (2012a) 'Again the most vulnerable suffer' The Guardian, 7 September 2012a. Accessed on 13/08/15 at http://www.guardian.co.uk/society/2012/sep/07/again-the-most-vulnerable-suffer. Ward, H. (2012b) 'Taking children into care can only be a sticking-plaster solution' The Guardian, 21 November 2012b. Accessed on 13/08/15 at http://www.guardian.co.uk/society/2012/nov/21/taking-children-care-sticking-plastersolution.

Ward, H. (2014) The Impact of Neglect and Other Forms of Abuse on Children's Well-being: Implications for Practice. Keynote Presentation to Yorkshire and Humberside Adoption Consortium: Thinking Permanence Conference, July, 2014. Ward, H. (2015) Anti-poverty roundtable: Prisoners and Looked after Children - A Common Cause? Comment, Criminal Justice Matters.

$\mathrm{R}$ (on the application of SG and others (previously JS and others) v Secretary of State for Work and Pensions (2015) UKSC 16. 